\title{
A LEITURA EM MOVIMENTO: ESTUDO DE UM CASO DE CENSURA NO BRASIL DO SÉCULO XIX
}

\author{
Fernando César da Silva Ramos*
}

RESUMO:

0 presente trabalho consiste numa leitura de leituras feitas a respeito de certas passagens de 0s Lusíadas, no decorrer de sua história, com destaque para as considerações de frei Bartolomeu Ferreira, em 1571, e de Abílio César Borges, em 1879.

PALAVRAS-CHAVE: datas, leitura, efeito, recepção, censura.

Alfredo Bosi concebe as datas como sendo as mais indicadas como ponto de orientação, comparando-as a pontas de icebergs; definindo-as como índices de massas ocultas que fixam a relação entre o acontecimento e a polifonia do tempo social, do tempo cultural, do tempo corporal, que pulsa sob a linha de superfície dos eventos. Adverte-nos Bosi que só é possível entender o que aparece na vida em sociedade se examinarmos, por dentro, as vaidades e veleidades dos seus atores (Bosi, 1991: 19). E o desejo de examinar, mais particularmente, dois desses atores enquanto leitores, nasce da visão de uma ponta de iceberg, precisamente o ano de 1879, quando vem a público uma edição de Os Lusíadas, com a singular advertência estampada na capa: "Edição publicada pelo Dr. Abílio César Borges, para uso das escolas brasileiras, na qual se acham supressas todas as estâncias que não devem ser lidas pelos meninos". (Borges, 1879)

A visão dessa primeira ponta de iceberg leva nos a uma outra ponta, que é o ano de 1571, quando Os Lusíadas foi submetido ao exame do Tribunal do Santo Ofício, a fim de receber licença para impressão. Primeiro, um alvará expedido por el-rei D. Sebastião, ${ }^{1}$ mas

* Mestre em Letras: Literatura, História e Memória Cultural (Área de concentração: Literatura Brasileira), 2004. 


\section{EMTESE}

Belo Horizonte, v. 9, p. I-28I, dez. 2005

(...) antes de se imprimir será vista e examinada na mesa do Conselho Geral do Santo Ofício da Inquisição pera com sua licença se haver de imprimir, e se o dito Luís de Camões tiver acrescentados mais alguns cantos, também se imprimirão havendo pera isso licença do Santo Ofício, como acima foi dito. (Bueno, 1969: 16)

Acima da permissão real estava a do Santo Ofício, criado com o intuito de proteger a fé católica e seus preceitos morais. E tal proteção baseava-se, sobretudo, no controle das idéias divergentes, e de seus veículos de expressão, principalmente a palavra escrita. Era missão do Tribunal do Santo Ofício decidir o que poderia ou não ser lido. Vê-se, então, que o horizonte de expectativa dos leitores daquela época estava, à primeira vista, limitado àquilo que conviesse aos interesses da Igreja Católica, ou seja, textos com efeito e recepção previstos. Façamos, então, um retorno ao século XVI, 1571, e leiamos o parecer de frei Bartolomeu Ferreira, registrado na $1^{a}$ edição de Os Lusíadas, em 1572

Vi por mandado da Santa \& Geral Inquisição estes dez Cantos dos Lusíadas de Luís de Camões, dos valerosos feitos em armas que os Portugueses fizerão em Ásia \& Europa, e não achey nelles cousa algua escandalosa nem contrária â fé $\&$ os bõs costumes, somente me pareceo que era necessario aduertir os Lectores que o Autor pera encarecer a difficuldade da navegação \& entrada dos Portugueses na India, usa de hua fição dos Deoses dos Gentios. E ainda que sancto Augustinho nas suas Retractações se retracte de ter chamado nos liuros que compos de Ordine, aas Musas Deosas. Toda via como isto he Poesia e fingimento, \& 0 Autor como poeta, não pretende mais que ornar o estilo Poetico não tiuemos por inconueniente yr esta fabula dos Deoses na obra, conhecendoa por tal, \& ficando sempre salua a verdade de nossa sancta fe, que todos os Deoses dos Gentios sam Demonios. E por isso me pareceo o liuro digno de se imprimir, \& o Autor mostra nelle muito engenho \& muita erudição nas sciencias humanas. Em fe do qual assiney aqui.(Bueno, 1969: 17-18)

Os elementos que, de imediato, chamaram a atenção do inquisidor foram aqueles relativos à presença dos deuses dos gentios, mas o referido inquisidor trata-os como presença justificável, enfatizando que o autor utiliza-os com fim ornamental, nada mais que poesia e fingimento. Cleonice Berardinelli fala em duas razões como justificativa para a liberação do poema, ambas dizendo respeito ao fazer poético

A primeira remeteria ao emprego de um tipo de comparantes que encarecessem o valor dos personagens épicos, só equiparáveis a deuses; a segunda incorporaria a primeira, acrescentando-lhe o caráter ornamental. Motivos retóricos, pois, para justificar a aceitação de um texto como tal; estes é que são vălidos e justos, e não os éticos - principalmente religiosos 
- que seriam de se esperar do censor de uma instituição como o Santo ofício. (Berardinelli, 1993: 65)

Não devemos nos esquecer de que o próprio Camões, tanto no Canto IX, estâncias 89, 90, 91 e 92, como no Canto X, estância 82, se encarrega, pela boca de Vênus, de questionar todo o discurso mitológico/poético, nelas sintetizando as idéias de Evêmero (Nogueira, 1960: 173), filósofo grego do século IV a.C., que dizia serem os deuses homens notáveis, que se distinguiram em vida e deixaram a tradição de seus feitos, divinizados pelo povo.

Contudo, não podemos deixar de notar a argumentação do frei Bartolomeu Ferreira, que, como bem frisou Cleonice Berardinelli, teve a mente arejada pelos ventos renascentistas que sopravam da Itália, uma vez que justificou a presença dos deuses, no poema, como elemento retórico, como ornamento e ficção. Há uma consonância entre a leitura feita por frei Bartolomeu e o momento literário, e não religioso, da época em que vivia. Quando era de se esperar que o frei usasse outros critérios, ele contraria as expectativas e libera o poema, na íntegra. No entanto, doze anos mais tarde, outros ventos irão soprar, ventos intolerantes e repressivos. Para a edição de 1584 (conhecida como a dos Piscos), informa-nos Berardinelli, o parecer do mesmo frei encolheu e o poema também

Não só foi cortado, alterado e desvirtuado em muitas passagens, e por motivos ideológicos, porque alguns passos atentavam contra a fé e os bons costumes - ponto de vista ético-religioso - e porque outros eram agressivos aos castelhanos - ponto de vista politico. (Berardinelli, 1993: 64-65)

Ainda que, em 1584, o frei Bartolomeu tenha mudado seu parecer, devemos levar em conta que Portugal já estava sob domínio espanhol, desde 1580, o que seria uma atenuante para essa outra leitura, que acarretará modificações no poema. Então, as circunstâncias sócio-históricas influenciariam a recepção do poema. 0 horizonte de expectativa já não é o mesmo, sofrera substancial alteração. Outro público demandava o poema e o frei Bartolomeu se viu forçado a rever suas posições. Para Berardinelli, o "benemérito censor teria sucumbido a uma força maior: a do domínio espanhol que se manifestaria, sobretudo na repressão política e religiosa" (Berardinelli, 1993: 66). A mudança de horizonte à qual o censor estava obrigado a corresponder, caracterizava-se pela total intolerância. Acabou por substituir palavras, 


\section{EM TESE}

Belo Horizonte, v. 9, p. I-28I, dez. 2005

trocar versos inteiros, nem sempre respeitando a métrica, até suprimir algumas estâncias. Nas palavras de J.S. Silva Dias, em Camões no Portugal de Quinhentos

A Inquisição organizou e concentrou nas suas mãos uma máquina complexa para a supressão da leitura ou posse de livros com doutrina heterodoxa ou saídos da pena de autores teologicamente mal reputados. A margem de possibilidade para a leitura de textos evidentemente não ortodoxos tornou-se cada vez mais estreita e é quase inexistente nos finais do século XVI. (Dias, 1981)

Nota-se que Os Lusíadas nasceu e cresceu dentro de um contexto bastante conturbado e que sua história está intrinsecamente ligada à situação política e religiosa do Portugal do século XVI, época marcada pela "dureza da repressão, a recusa sistemática do direito à dissidência, o recurso ao obscurantismo como instrumento de contenção política, o lançamento de um ensino de conteúdo monolítico" (Dias, 1981). Como bem observou Alberto Manguel, a censura

(...) é o corolário de todo poder, e a história da leitura está iluminada por uma fileira interminável de fogueiras acesas por censores, dos primeiros rolos de papiro aos livros de nossa época. As obras de Protágoras foram queimadas em 411 A.C., em Atenas. No ano de 213 A.C., o imperador chinês Chi Huang-Ti tentou acabar com a leitura queimando todos os livros de seu reino. Em 168 A.C., a biblioteca judaica de Jerusalém foi deliberadamente destruída durante o levante dos macabeus. No primeiro século da era cristã, Augusto exilou os poetas Cornélio Galo e Ovídio e baniu suas obras. (Manguel, 1997: 315)

0 controle do poder religioso católico esteve constantemente ameaçado pela palavra escrita, por isso a vigilância constante exercida pelo Tribunal da Inquisição, um dos principais exemplos de veto às possibilidades de leituras diversas, com receio do que essas leituras pudessem despertar no íntimo de cada um. A leitura da Bíblia chegou a ser proibida, num momento em que o protestantismo adotava a livre interpretação dos textos sagrados.

Quanto à leitura de Abilio, realizada mais de trezentos anos depois, percebe-se nela uma visão extremamente moralista, e principalmente, subjetiva, uma vez que atribui a necessidade de expurgo das estâncias ao seu constrangimento, quando, na sala de aula, abria o Camões ao acaso e se deparava com aquelas cenas de erotismo requintado, de lascivia brutal e monstruosa. Seria, verdadeiramente, o zelo pela moral, o único fator que levou 
Abîlio César Borges a publicar uma edição de Os Lusíadas, diminuída de 34 estâncias, influenciado talvez pelo puritanismo vitoriano? Se fosse o zelo pela moral, por que Abílio não efetuou a censura em 1858, ano em que fundou 0 Ginásio Baiano, e mesmo ano em que, na Europa, Gustave Flaubert, Charles Baudelaire e Eugéne Sue, sofriam processos por escreverem livros considerados ofensivos à moral pública? Sem dúvida seria uma excelente ocasião.

Ou quem sabe, teria sido sua vaidade? Talvez, como a de Aristarco Argolo de Ramos, caricatura de Abílio César Borges, criada por Raul Pompéia, em 0 Ateneu, romance publicado em 1888, portanto, nove anos depois da ediçãoAbílio de Os Lusíadas. É necessário frisar que Raul Pompéia foi aluno interno do Colégio Abílio, no Rio de Janeiro, entre 1873 e 1878. Vejamos o trecho do referido romance em que o narrador Sérgio é convidado por Sanches a lerem, juntos, determinadas passagens do Canto IX, de Os Lusíadas. É bem possível que a edição-Abílio tenha fornecido a matéria-prima para esta e outras passagens de 0 Ateneu.

Inventou uma análise dos Lusíadas, livro de exame, cuja dificuldade não cessava de encarecer.

Guiou-me ao canto nono, como a uma rua suspeita. Eu gozava criminosamente o sobressal to dos inesperados. Mentor levou-me por diante das estrofes, rasgando na face nobre do poema perspectivas de bordel a fumegar alfazema. Bárbaro! Havia um trajo de modéstia sobre a verdade do vocábulo; ele rasgava as túnicas de alto a baixo, grosseiramente. Fazia do meneio grácil de cada verso uma brutalidade ofensiva. Eu acompanhava-o sem remorso; reputava-me vagamente vítima, e me dava à crueldade, submisso, adormecido na vantagem da passividade. A análise aguilhoava as rimas; as rimas passavam, deixando a lembrança de um requebro impudente. E o ar severo do Sanches imperturbável. Tomava cada período, cada oração, altamente, com o ademã sisudo do anatomista: sujeito, verbo, complementos, orações subordinadas; depois o significado, záz! Um corte de escalpelo, e a frase rolava morta, repugnante, desentranhandose em podridões infectas. (Pompéia, 1983: 40)

Por que, somente depois de vinte anos atuando como educador, resolveu agir em relação a certas passagens do poema? Interessante que no prefácio a sua edição de Os Lusíadas, Abílio faz menção a um certo professor H. Perret, que o induziu a

(...) ler e reler o Camões, e levou sua complacência até o excesso de prestar-se a lel-o e analysal-o commigo, fazendo-me notar, uma por uma, todas as preciosidades, que a cada passo no mesmo se deparam. De tal 


\section{EM TESE}

Belo Horizonte, v. 9, p. I-28I, dez. 2005

gosto e admiração tomei-me desde então pelo poema dos Lusíadas, que nunca mais, até o presente, deixei de tel-o por companheiro inseparavel. E com tal frequencia o lia, que cheguei a decoral-o quasi todo. (Borges, 1879: IV)

Que influências teria exercido o professor $H$. Perret no jovem Abílio, durante as leituras, para que o tornasse quase uma espécie de fanático pelos Lusíadas? Teriam lido a edição integral, e se leram, de que forma teriam sido encaradas passagens consideradas portadoras de grande carga erótica? Da mesma forma que Sanches leu para Sérgio? Parece-nos que Pompéia faz uma paródia ao trecho citado do prefácio de Abílio. Que motivos tão graves levariam alguém a mutilar seu próprio objeto de culto? Somente o constrangimento? Haveria uma demanda tão grande de leitores que justificasse a publicação? É pertinente, aqui, comparar a leitura de determinadas passagens de Os Lusíadas, feita por Abílio, com outra, e vem a calhar a leitura do Conselheiro Paulino, em seu discurso crítico e apologético, introdutório a uma edição do poema, por ele publicada em 1865

A ternura e melindres com que pinta a Vênus lastimada, diante de Júpiter, no canto II, pedindo-1he socorro e favor para os navegantes. (...) Parece impossível, que o mesmo espírito que descreveu a cólera de um $D$. Nuno Álvares Pereira, e o sanguinolento daquela batalha no canto IV, e no mesmo o furioso daquela tormenta, pudesse transformar-se nas ternuras que contém todo o canto IX; e principalmente no amoroso Leonardo, para dizer à sua Ninfa as altas, suaves, e finas expressões, que ali se lêem. (Souza, 1865: 6)

Onde Abílio César Borges vê cenas de requintado erotismo e lascívia brutal e monstruosa, o conselheiro Paulino vê ternura, suaves e finas expressões. 0 que se constata nas argumentações de Abílio, talhadas sempre com grande eloqüência, é que sua censura está diretamente ligada a questões relativas à sexualidade. Por que ocultar dos jovens, pelo maior espaço de tempo possível, as questões relativas ao sexo? Funcionaria essa pedagogia do ocultamento? Provém de que formação a mentalidade de Abilio, para ver na sexualidade algo perigoso, que deva permanecer distante da realidade dos meninos e meninas?

De acordo com as pesquisas de Leonardo Arroyo, na Biblioteca Nacional do Rio de Janeiro, entre 1856 e 1892, foram publicadas dez edições de Os Lusíadas, no Brasil, sendo a de Abílio a sétima na ordem cronológica e a 
primeira a aparecer censurada. 0 professor H. Perret e Abílio, portanto, não leram uma edição brasileira. 0 estudioso adverte que seu inventário pode estar incompleto, pois muitas edições não se encontram registradas em bibliotecas, sendo também difícil a diferenciação entre uma edição escolar ou popular, já que ambas trazem o necessário aparato didático, como por exemplo a de Francisco Sales de Lencastre, destinada à "leitura da infância e do povo" (1892). Outra edição, que o pesquisador vê como singular, é a do Barão de Paranapiacaba (1886), que elimina 55 estâncias dos Cantos IX e X e

(...) efetuou a "modernização" de Os Lusíadas sob o título de Camoniana Brasileira. Do poema fez o barão uma salada de frutas, acompanhando-a de extenso número de notas a respeito de mitologia, numa pueril demonstração de erudição tão grande e vaidosa que Sílvio Romero o glosou em sua História da Literatura Brasileira e de certo modo até impiedoso. (Souza, 1865: 6)

Leonardo Arroyo constata que a tradição de leitura de Os Lusíadas, no Brasil, é muito antiga, pois no inventário do bandeirante Pero de Araújo, integrante da bandeira do Capitão Antônio Pedroso de Alvarenga, foram encontradas quatro estâncias do Canto V, anotadas pelo escrivão da bandeira, no verso de um documento (1616). Contudo, foi no Império que se deu a expansão da leitura do épico camoniano nas escolas brasileiras, tendo sido o poeta Cruz e Souza dos primeiros a se rebelar contra o ensino do português através do poema, chegando mesmo a chamá-1o de compêndio de geografia em verso, anacrônico e parvo, cheirando a Olimpo e a negócio, informa-nos o cronista carioca Luís Edmundo (Apud Arroyo, 1990: 92). Outro relato interessante, feito pelo cronista Luís Edmundo, dá conta da história de um menino, chamado Luís de Souza e Costa, que, revoltado contra o ensino do Português, abre um buraco no fundo do quintal de sua casa, e ali enterra o poema de Camões, juntamente com os cadernos de gramática.

Segundo Leonardo Arroyo, ninguém como o cronista Luís Edmundo fixou com tanta "precisão e realidade", o aprendizado da língua através dos clássicos portugueses, principalmente em Os Lusíadas

Lembra o memorialista que o "método era 0 de estudar a língua que falamos pelos livros dos velhos clássicos lusos, modo indireto de indispor as crianças contra os grandes artífices do idioma", ao mesmo tempo que evoca, no Colégio Abílio César Borges, o Professor Lino de Andrade que, 


\section{EMTESE}

Belo Horizonte, v. 9, p. I-28I, dez. 2005

"como os pedagogos de seu tempo, não queria acreditar que as línguas vão aos poucos se transformando à revelia da vontade humana e que as nossas formas de expressão são mais filhas da natureza que da história". Excluía-se assim, no ensino, o que Luís Edmundo, em fins do século passado, já chamava de "espírito da época" e "sentimento nacional". (Apud Arroyo, 1990: 92)

É bem possível que os alunos de Abílio César Borges, ao invés de se interessarem pelos estudos de Gramática Filosófica e Retórica, preferissem iniciar-se nos mistérios do amor, lendo algumas estâncias de Os Lusíadas. Confessa o próprio Luís Edmundo, que foi aluno do Colégio Abílio

(...) tais pontos, verdadeiros convites à nossa curiosidade, serviam-nos de fácil indicação para as descobertas das passagens que, no poema, eram consideradas indiscretas, abrejeiradas ou maliciosas. Em muitas delas, embora lidas e relidas com cuidado, não achávamos logo as razões do censor em suprimi-las. (Edmundo, 1937: 273)

A censura de Abílio pareceu-nos estar dotada de forças contraditórias, paradoxais. Por um lado, o teor moralizante explícito na seleção do que deva ou não ser lido pelos meninos. Vislumbra-se, aqui, a configuração pretensiosa de um leitor padrão, instância maior capaz de decidir, por todos, o que seja conveniente ser lido, ou não. Um juiz das e para as consciências, como mais tarde viria a se constituir o frei Pedro Sinzig, organizador da obra Através dos Romances, na qual foram catalogados e julgados recomendáveis ou não, do ponto de vista estritamente moral, cerca de 5000 romances. De outro lado, implícita, está a carga de incitação que carrega a censura: o aguçamento da curiosidade, o despertar do desejo e a ânsia de conhecer o que foi proibido e por qual motivo.

Não se pode negar que, tanto as considerações feitas por frei Bartolomeu, quanto as feitas por Abílio, de uma maneira ou de outra, influenciam os leitores, no momento da recepção do poema. E, certamente, que a grande interferência é a realizada por Abilio, agindo diretamente sobre o horizonte de expectativas dos possíveis leitores de sua edição. Parece que não aceitariam, de bom grado, a intervenção no poema. Teriam a curiosidade açulada por aquilo que thes foi ocultado, como disse o próprio Luis Edmundo, ainda mais que o próprio Abílio facilitou a localização das estâncias censuradas, substituindo-as por linhas pontilhadas. 
Como bem argumentou Hans Robert Jauss (Jauss, 1994: 30), a literatura não pode ser privada das dimensões de recepção e efeito. É imprescindível o papel do leitor, tanto para o conhecimento estético quanto para o histórico, já que a relação entre literatura e leitor possui implicações tanto estéticas quanto históricas, sendo que as estéticas se devem ao fato de a recepção primária de uma obra pelo leitor levá-1o a uma comparação com outras lidas anteriormente. As implicações históricas manifestam-se na possibilidade de, numa cadeia de recepções, a compreensão dos primeiros leitores ter continuidade e enriquecer-se de geração em geração. De acordo com Antônio Candido, o público leitor dá sentido e realidade à obra, e sem ele o autor não se realiza, uma vez que esse público, de certo modo, transforma-se em espelho que reflete a imagem do autor enquanto criador (Candido, 1973: 38). É a leitura quem movimenta o texto, reativando-o, tirando-o da inércia das páginas, transformandoo num organismo vivo, múltiplo em significado.

NOTA

1 As citações do alvará e dos prefácios respeitarão a ortografia vigente em cada época de publicação.

ABSTRACT :

This work consists in the study about of Os Lusiadas, in two distinct moments of the history. First, related to 1571, the date for the permission of the edition, when it was analysed by the Saint Occupation's Tribunal. The second, related to 1879, the year that 0s Lusiadas was published by the doctor and pedagogue Abilio César Borges.

KEY WORDS: dates, reading, effects, reception, censure. 


\title{
EMTESE
}

Belo Horizonte, v. 9, p. I-28I, dez. 2005

\author{
REFERÊNCIAS BIBLIOGRÁFICAS
}

ARROYO, Leonardo. Literatura Infantil Brasileira. 10. ed. São Paulo: Melhoramentos, 1990.

BERARDINELLI, Cleonice. De censores e de censura Rio de Janeiro: Palavra, 1993.

BETHENCOURT, Francisco. A História das Inquisições. São Paulo: Cia. das Letras, 2000.

BOSI, Alfredo. "0 Tempo e os Tempos". In: Tempo $e$ História. São Paulo: Cia. das Letras, 1991.

CAMÕES, Luís Vaz de. Os Lusíadas. Editor: Abílio César Borges. Bruxelas: Typographia \& Lithographia E. Guyot, 1879 . $\overline{18} \overline{6}$.

- Os Lusíadas. Editor: Paulino de Souza. Paris,

- Os Lusíadas. Edição crítica de Francisco da Silveira Bueno. Rio de Janeiro: Tecnoprint Gráfica Editora. 1969.

CANDID0, Antonio. Literatura e sociedade. 3. ed. São Paulo: Companhia Editora Nacional, 1973.

DIAS, J.S. da Silva. Camões no Portugal de Quinhentos. 1 aed. Lisboa: Livraria Bertrand, 1981.

EDMUNDO, Luís. O Rio de Janeiro do meu tempo. Rio de Janeiro: Imprensa Nacional, 1938.

- De um Livro de Memórias. Rio de Janeiro: Departamento de Imprensa Nacional, 1958.

JAUSS, Hans Robert. A História da Literatura como Provocação à Teoria Literária. Trad. Sérgio Tellaroli. São Paulo: Ática, 1994.

MANGUEL, Alberto. Uma História da Leitura. Trad. Pedro M. Soares. São Paulo: Cia. das Letras, 1997.

NOGUEIRA, Julio. Dicionário e Gramática de Os Lusíadas. São Paulo: Livraria Freitas Bastos, 1960.

POMPÉIA, Raul. O Ateneu. São Paulo: Editora Moderna, 1983. 